\title{
BMJ
}

\section{The prevention of progression of arterial disease and diabetes (POPADAD) trial: factorial randomised placebo controlled trial of aspirin and antioxidants in patients with diabetes and asymptomatic peripheral arterial disease}

\author{
Jill Belch, professor of vascular medicine, ${ }^{1}$ Angus MacCuish, consultant diabetologist, ${ }^{2}$ lain Campbell, \\ professor of diabetic medicine, ${ }^{3}$ Stuart Cobbe, Walton professor of cardiology, ${ }^{4}$ Roy Taylor, professor of \\ medicine and metabolism, ${ }^{5}$ Robin Prescott, professor of health technology assessment, ${ }^{8}$ Robert Lee, \\ research associate, ${ }^{8}$ Jean Bancroft, senior research nurse, ${ }^{1}$ Shirley MacEwan, honorary senior research \\ fellow, ${ }^{1}$ James Shepherd, professor of pathological biochemistry, ${ }^{6}$ Peter Macfarlane, professor of \\ electrocardiology, ${ }^{7}$ Andrew Morris, professor of diabetic medicine, ${ }^{9}$ Roland Jung, consultant physician \\ (endocrine and diabetes) and honorary professor of medicine, ${ }^{10}$ Christopher Kelly, consultant \\ diabetologist, ${ }^{11}$ Alan Connacher, consultant diabetologist and endocrinologist, ${ }^{12}$ Norman Peden, consultant \\ diabetologist, ${ }^{13}$ Andrew Jamieson, consultant physician, ${ }^{14}$ David Matthews, consultant physician, ${ }^{15}$ Graeme \\ Leese, consultant endocrinologist, John McKnight, consultant physician and honorary senior lecturer, ${ }^{16}$ lain \\ O'Brien, consultant diabetologist, ${ }^{17}$ Colin Semple, consultant physician, ${ }^{18}$ John Petrie, reader in diabetes, ${ }^{9}$ \\ Derek Gordon, consultant physician, ${ }^{19}$ Stuart Pringle, professor of cardiology, ${ }^{20}$ Ron MacWalter, consultant \\ stroke physician, ${ }^{1}$ on behalf of the Prevention of Progression of Arterial Disease and Diabetes Study Group, \\ Diabetes Registry Group, and Royal College of Physicians Edinburgh
}

\footnotetext{
Institute of Cardiovascular Research, University of Dundee, Ninewells Hospital, Dundee DD1 9SY

${ }^{2}$ Diabetes Centre, Glasgow Royal Infirmary

${ }^{3}$ Department of Medicine, Royal Victoria Hospital, Kirkcaldy

${ }^{4}$ British Heart Foundation Glasgow Cardiovascular Research Centre, University of Glasgow

${ }^{5}$ Royal Victoria Infirmary, Newcastle upon Tyne

${ }^{6}$ Department of Biochemistry, Glasgow Royal Infirmary

${ }^{7}$ Department of Medical Cardiology, Glasgow Royal Infirmary

${ }^{8}$ Medical Statistics Unit, University of Edinburgh

${ }^{9}$ Diabetes Research Centre,

Ninewells Hospital

${ }^{10}$ Diabetes and Endocrinology, Ninewells Hospital

${ }^{11}$ Diabetes Centre, Stirling Royal Infirmary

${ }^{12}$ Diabetes Centre, Perth Royal Infirmary

${ }^{13}$ Diabetes Centre, Falkirk and District Royal Infirmary, Falkirk

${ }^{14}$ Diabetes Centre, Queen Margaret Hospital, Dunfermline
}

\section{ABSTRACT}

Objective To determine whether aspirin and antioxidant therapy, combined or alone, are more effective than placebo in reducing the development of cardiovascular events in patients with diabetes mellitus and asymptomatic peripheral arterial disease.

Design Multicentre, randomised, double blind, $2 \times 2$ factorial, placebo controlled trial.

Setting 16 hospital centres in Scotland, supported by 188 primary care groups.

Participants 1276 adults aged 40 or more with type 1 or type 2 diabetes and an ankle brachial pressure index of 0.99 or less but no symptomatic cardiovascular disease. Interventions Daily, $100 \mathrm{mg}$ aspirin tablet plus antioxidant capsule $(n=320)$, aspirin tablet plus placebo capsule $(n=318)$, placebo tablet plus antioxidant capsule $(n=320)$, or placebo tablet plus placebo capsule $(n=318)$. Main outcome measures Two hierarchical composite primary end points of death from coronary heart disease or stroke, non-fatal myocardial infarction or stroke, or amputation above the ankle for critical limb ischaemia; and death from coronary heart disease or stroke.

Results No evidence was found of any interaction between aspirin and antioxidant. Overall, 116 of 638 primary events occurred in the aspirin groups compared with 117 of 638 in the no aspirin groups (18.2\% v 18.3\%): hazard ratio 0.98 (95\% confidence interval 0.76 to 1.26$)$. Forty three deaths from coronary heart disease or stroke occurred in the aspirin groups compared with 35 in the no aspirin groups (6.7\% v 5.5\%): 1.23 (0.79 to 1.93 ). Among the antioxidant groups 117 of $640(18.3 \%)$ primary events occurred compared with 116 of $636(18.2 \%)$ in the no antioxidant groups (1.03, 0.79 to 1.33$)$. Forty two (6.6\%) deaths from coronary heart disease or stroke occurred in the antioxidant groups compared with $36(5.7 \%)$ in the no antioxidant groups (1.21, 0.78 to 1.89$)$.

Conclusion This trial does not provide evidence to support the use of aspirin or antioxidants in primary prevention of cardiovascular events and mortality in the population with diabetes studied.

Trial registration Current Controlled Trials ISRCTN53295293.

\section{INTRODUCTION}

Cardiovascular disease is the major cause of morbidity and mortality in patients with type 1 or type 2 diabetes mellitus. These patients have been reported to have an overall mortality of $50 \%$ within 40 years of diagnosis compared with only $10 \%$ in a control population. ${ }^{1}$ This increased mortality is mainly from ischaemic heart disease ${ }^{23}$ and cerebrovascular disease, the incidence of which is reported to be twofold to fivefold greater $^{45}$ than the general population without diabetes.

Peripheral arterial disease is another powerful indicator of systemic atheroma. Regardless of whether symptoms are evident, ${ }^{6}$ patients with peripheral 
${ }^{15}$ Diabetes Centre, Monklands Hospital, Airdrie

${ }^{16}$ Metabolic Unit, Western General Hospital, Edinburgh

${ }^{17}$ Wishaw General Hospital, Wishaw

${ }^{18}$ Southern General Hospital NHS Trust, Glasgow

${ }^{19}$ Medical Unit B, Stobhill NHS Trust, Glasgow

${ }^{20}$ Cardiology Department, Ninewells Hospital

Correspondence to: J Belch

J.J.F.Belch@dundee.ac.uk

Cite this as: $B M J$ 2008;337:a1840 doi:10.1136/bmj.a1840 arterial disease have an increased risk of subsequent myocardial infarction and stroke and are six times more likely to die from cardiovascular disease within 10 years than patients without peripheral arterial disease. ${ }^{7}$ Patients with peripheral arterial disease have a 15 year accrued survival rate of about $22 \%$ compared with a survival rate of $78 \%$ in patients without such disease. $^{89}$

The use of antiplatelet agents is known to reduce future secondary cardiovascular events in patients with both diabetes mellitus and cardiovascular disease ${ }^{45}$ and in patients with peripheral arterial disease. ${ }^{410}$ In the population with peripheral arterial disease the results were driven mainly by non-aspirin antiplatelet drugs, although it is often, and incorrectly, assumed that the antiplatelet drug studied in peripheral arterial disease was aspirin. The strength of the evidence for use of antiplatelet agents as secondary prevention in these groups $^{11-14}$ has, however, led to the suggestion that aspirin might be useful for primary prevention in both diabetes and asymptomatic peripheral arterial disease. These recommendations have been incorporated into international society guidelines such as the joint societies guidelines, ${ }^{15}$ and national guidelines such as the prevention guideline on coronary artery disease from the Scottish Intercollegiate Guidelines Network, ${ }^{16}$ the American Heart Association, ${ }^{17}$ the American Diabetes Association, ${ }^{18}$ and the American College of Cardiology guidelines on peripheral arterial disease. ${ }^{19}$ These guidelines are published despite the evidence from the antithrombotic trialist metaanalysis $^{4}$ that showed no benefit from antiplatelet therapy for primary prevention in people with diabetes. Few data are available on aspirin for primary prevention in patients with diabetes. The primary prevention project trial ${ }^{20}$ compared aspirin with placebo in patients with type 2 diabetes without established cardiovascular disease. Aspirin failed to achieve a significant difference in the composite cardiovascular end point. Evidence is also conflicting on the effects of aspirin on stroke outcomes in patients

\begin{tabular}{|c|c|c|c|}
\hline \multicolumn{4}{|c|}{ Eligible patients $(n=1670)$} \\
\hline & & $\rightarrow$ Refu & to participate $(n=394)$ \\
\hline \multicolumn{4}{|c|}{ Randomised $(n=1276)$} \\
\hline$\sqrt{ }$ & $\downarrow$ & $\downarrow$ & $\downarrow$ \\
\hline $\begin{array}{c}\text { Aspirin plus } \\
\text { antioxidant }(n=320)\end{array}$ & $\begin{array}{c}\text { Aspirin plus } \\
\text { placebo }(n=318)\end{array}$ & $\begin{array}{c}\text { Placebo plus } \\
\text { antioxidant }(n=320)\end{array}$ & $\begin{array}{c}\text { Placebo plus } \\
\text { placebo }(n=318)\end{array}$ \\
\hline$\downarrow$ & $\downarrow$ & $\downarrow$ & $\downarrow$ \\
\hline $\begin{array}{l}\text { Follow-up in } 2006 \\
(n=260)\end{array}$ & $\begin{array}{l}\text { Follow-up in } 2006 \\
(n=279)\end{array}$ & $\begin{array}{l}\text { Follow-up in } 2006 \\
(n=260)\end{array}$ & $\begin{array}{l}\text { Follow-up in } 2006 \\
(n=275)\end{array}$ \\
\hline Died $(n=56)$ & Died $(n=38)$ & Died $(n=59)$ & Died $(n=42)$ \\
\hline $\begin{array}{l}\text { Lost to follow-up } \\
(n=3)\end{array}$ & $\begin{array}{l}\text { Lost to follow-up } \\
(n=1)\end{array}$ & $\begin{array}{l}\text { Lost to follow-up } \\
(n=1)\end{array}$ & $\begin{array}{l}\text { Lost to follow-up } \\
(n=1)\end{array}$ \\
\hline $\begin{array}{l}\text { Withdrew consent } \\
(\mathrm{n}=1)\end{array}$ & $\begin{array}{l}\text { Withdrew consent } \\
(\mathrm{n}=0)\end{array}$ & $\begin{array}{l}\text { Withdrew consent } \\
(n=0)\end{array}$ & $\begin{array}{l}\text { Withdrew consent } \\
(n=0)\end{array}$ \\
\hline
\end{tabular}

Fig 1| Progress of participants in trial

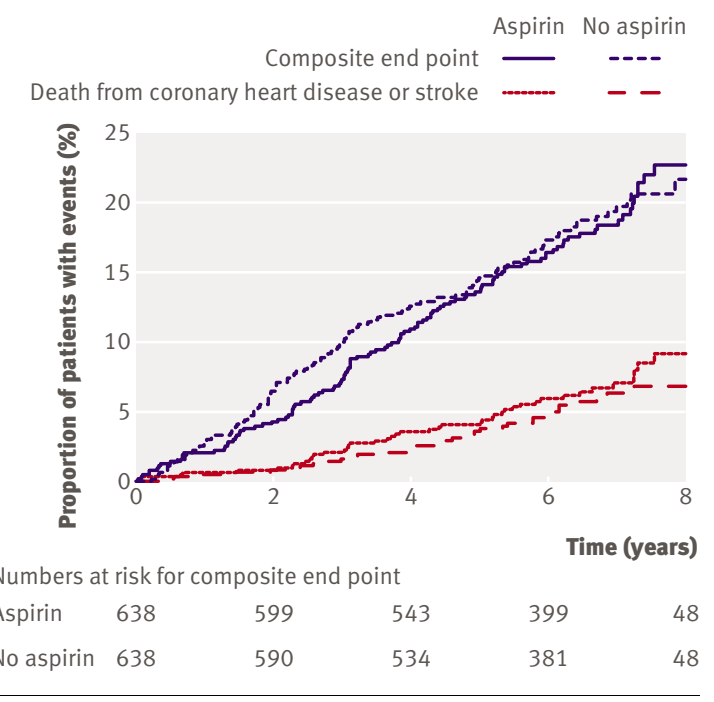

\begin{tabular}{l|l}
\hline Fig 2 & Kaplan-Meier estimates in aspirin and no aspirin groups
\end{tabular} of proportion of patients who experienced the composite end point of death from coronary heart disease or stroke, non-fatal myocardial infarction or stroke, or above ankle amputation for critical limb ischaemia; and death from coronary heart disease or stroke

with diabetes. ${ }^{21}$ Despite the guidelines' recommendations, antiplatelet uptake as a primary prevention in diabetes has been low, reflecting the uncertainty of the value of this therapy, combined with the knowledge of the significant side effects that can be associated with aspirin usage. $^{2223}$

A meta-analysis ${ }^{24}$ of four randomised controlled trials of aspirin as primary prophylaxis against cardiovascular events showed that although aspirin decreased the risk of myocardial infarction it did not reduce total mortality and might increase the risk of stroke and of major bleeding. That meta-analysis and another study ${ }^{25}$ concluded that on the basis of evidence from randomised controlled trials aspirin should not be given to all people with diabetes for primary prophylaxis of cardiovascular events but only to specific subgroups.

Several haemostatic and fibrinolytic abnormalities have been detected in patients with diabetes but the most compelling and reproducible abnormalities have been those of platelet behaviour, with enhanced release of platelet products and platelet aggregation ${ }^{26}$; thus the suggestion that aspirin and other antiplatelet agents may be beneficial. Links between platelet aggregation and the increase in oxidative stress seen in people with diabete ${ }^{27}$ and in those with peripheral arterial disease ${ }^{28}$ have been studied. Free radicals have been shown to increase platelet aggregation, with antioxidants decreasing aggregation. ${ }^{29}$ Defence against free radical attack is provided in part by the body's antioxidants. Plasma vitamin $\mathrm{E}$ and ascorbic acid levels are lowered in people with diabetes. Other scavengers have also been reported to be decreased in people with diabetes and in those with both diabetes and peripheral arterial disease compared with those with peripheral arterial disease but no diabetes. ${ }^{28}$ For these reasons interest has 
arisen in assessing antioxidant therapy in people with diabetes. ${ }^{27} \mathrm{We}$ determined whether aspirin and antioxidant therapy, combined or alone, are more effective than placebo in reducing the development of cardiovascular events in patients with diabetes and asymptomatic peripheral arterial disease.

\section{METHODS}

The prevention of progression of arterial disease and diabetes (POPADAD) trial was a multicentre, randomised, double blind, placebo controlled trial. We used a $2 \times 2$ factorial design ${ }^{30}$ to examine the efficacy and safety of aspirin plus antioxidant compared with aspirin alone, antioxidant alone, and placebo.

The interventions were daily aspirin $100 \mathrm{mg}$ or placebo tablet, plus antioxidant or placebo capsule. The antioxidant capsule contained $\alpha$-tocopherol $200 \mathrm{mg}$, ascorbic acid $100 \mathrm{mg}$, pyridoxine hydrochloride $25 \mathrm{mg}$, zinc sulphate $10 \mathrm{mg}$, nicotinamide $10 \mathrm{mg}$, lecithin $9.4 \mathrm{mg}$, and sodium selenite $0.8 \mathrm{mg}$. We selected this particular mix following advice from

Table 1|Baseline characteristics. Values are medians (interquartile ranges) unless stated otherwise

\begin{tabular}{|c|c|c|c|c|}
\hline Characteristics & $\begin{array}{l}\text { Aspirin plus } \\
\text { antioxidant } \\
(n=320)\end{array}$ & $\begin{array}{c}\text { Aspirin plus } \\
\text { placebo }(n=318)\end{array}$ & $\begin{array}{l}\text { Placebo plus } \\
\text { antioxidant } \\
(n=320)\end{array}$ & $\begin{array}{c}\text { Placebo plus } \\
\text { placebo }(n=318)\end{array}$ \\
\hline $\begin{array}{l}\text { Mean (SD) age } \\
\text { (years) }\end{array}$ & $61.0(10.0)$ & $60.0(10.1)$ & $60.0(10.3)$ & $60.1(9.7)$ \\
\hline No (\%) women & $169(53)$ & $183(58)$ & $181(57)$ & $180(57)$ \\
\hline $\begin{array}{l}\text { Time since diagnosis } \\
\text { of diabetes (years) }\end{array}$ & $6.7(2.9-12.9)$ & $6.0(2.7-13.0)$ & $5.7(2.4-11.7)$ & $6.4(2.6-11.6)$ \\
\hline $\begin{array}{l}\text { No (\%) treated with } \\
\text { insulin }\end{array}$ & 107 (33) & $112(35)$ & $96(30)$ & $91(29)$ \\
\hline \multicolumn{5}{|l|}{ Smoking status: } \\
\hline $\begin{array}{l}\text { No (\%) current } \\
\text { smokers }\end{array}$ & $105(33)$ & $99(31)$ & $106(33)$ & $87(27)$ \\
\hline $\begin{array}{l}\text { No (\%) former } \\
\text { smokers }\end{array}$ & $113(35)$ & $107(34)$ & $111(35)$ & $116(36)$ \\
\hline $\begin{array}{l}\text { No (\%) never } \\
\text { smokers }\end{array}$ & $102(32)$ & $112(35)$ & $103(32)$ & $115(36)$ \\
\hline $\begin{array}{l}\text { Body mass index }(\mathrm{kg} / \\
\left.\mathrm{m}^{2}\right)\end{array}$ & $29.7(26.2-33.3)$ & $28.7(25.2-33.0)$ & $29.4(26.1-33.5)$ & $29.2(25.8-33.2)$ \\
\hline $\begin{array}{l}\text { Mean (SD) systolic } \\
\text { blood pressure (mm } \\
\mathrm{Hg})\end{array}$ & $146(22)$ & $143(21)$ & $144(20)$ & $147(21)$ \\
\hline $\begin{array}{l}\text { Mean (SD) diastolic } \\
\text { blood pressure (mm } \\
\mathrm{Hg})\end{array}$ & $79(10)$ & $78(10)$ & $79(10)$ & 80 (11) \\
\hline $\begin{array}{l}\text { Ankle brachial } \\
\text { pressure index }\end{array}$ & $0.90(0.82-0.95)$ & $0.91(0.84-0.95)$ & $0.89(0.81-0.94)$ & $0.90(0.83-0.96)$ \\
\hline $\begin{array}{l}\text { Mean (SD) } \mathrm{HbA}_{1 \mathrm{c}} \\
\text { level (\%) }\end{array}$ & $8.0(1.8)$ & $8.0(1.7)$ & $7.9(1.8)$ & $7.9(1.7)$ \\
\hline $\begin{array}{l}\text { Total cholesterol } \\
\text { level }(\mathrm{mmol} / \mathrm{l})\end{array}$ & $5.5(4.8-6.2)$ & $5.6(4.9-6.2)$ & $5.5(4.9-6.3)$ & $5.5(4.9-6.2)$ \\
\hline $\begin{array}{l}\text { Triglyceride level } \\
(\mathrm{mmol} / \mathrm{l})\end{array}$ & $2.2(1.5-3.2)$ & $2.2(1.5-3.3)$ & $2.3(1.4-3.4)$ & $2.1(1.5-3.3)$ \\
\hline $\begin{array}{l}\text { High density } \\
\text { lipoprotein level } \\
(\mathrm{mmol} / \mathrm{l})\end{array}$ & $1.2(1.0-1.5)$ & $1.3(1.0-1.5)$ & $1.2(1.0-1.5)$ & $1.2(1.0-1.5)$ \\
\hline $\begin{array}{l}\text { Low density } \\
\text { lipoprotein level } \\
(\mathrm{mmol} / \mathrm{l})\end{array}$ & $3.1(2.5-3.7)$ & $3.1(2.5-3.7)$ & $3.2(2.6-3.9)$ & $3.1(2.6-3.7)$ \\
\hline
\end{tabular}

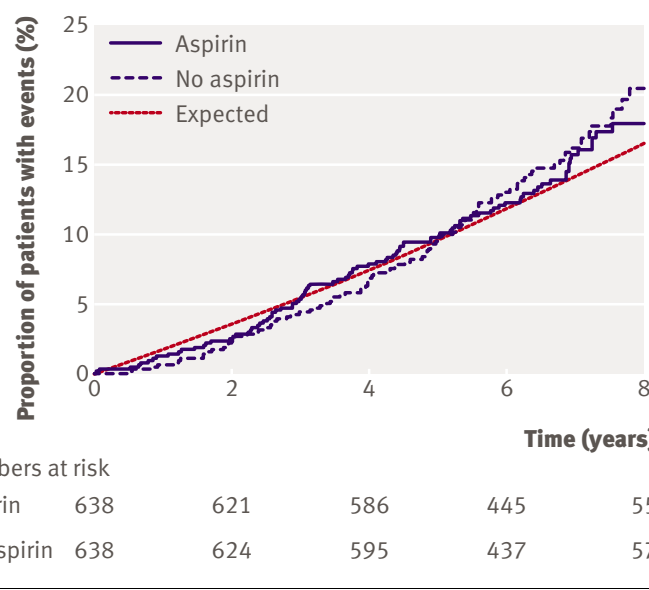

Fig 3 | Kaplan-Meier estimates for aspirin and no aspirin groups of proportion of patients who died from any cause, compared with proportion expected based on age and sex specific population rates for Scotland, 2002

experts in antioxidants, with approval of the Medicines' Control Agency for use as a nutritional aid in clinical studies. The placebo tablet and capsule were identical in appearance to the active tablet and capsule.

\section{Participants}

Participants were recruited by the Royal College of Physicians, Edinburgh, East of Scotland Diabetic Registry Group, which covers diabetic clinics in hospitals in the south east of Scotland and in central Scotland, and from clinics in the west of Scotland. The coordinating centre was Ninewells Hospital, Dundee. Sixteen hospital centres participated in the trial, supported by 188 primary care groups.

Inclusion criteria were adults of either sex, aged 40 or more, with type 1 or type 2 diabetes who were determined as having asymptomatic peripheral arterial disease as detected by a lower than normal ankle brachial pressure index $(\leq 0.99)$. We selected a higher cut-off point $(0.99 v 0.9)$ for the trial as it is recognised that calcification in the vessels of people with diabetes can produce normal or high ankle brachial pressure indexes, even in the presence of arterial disease. We excluded people with evidence of symptomatic cardiovascular disease; those who use aspirin or antioxidant therapy on a regular basis; those with peptic ulceration, severe dyspepsia, a bleeding disorder, or intolerance to aspirin; those with suspected serious physical illness (such as cancer), which might have been expected to curtail life expectancy; those with psychiatric illness (reported by their general practitioner); those with congenital heart disease; and those unable to give informed consent.

\section{Trial procedures}

Potentially eligible participants attending the diabetes clinics during the enrolment period were invited to join the trial. If they agreed they were screened for eligibility. We scrutinised each patient's hospital and general practice records for evidence of symptomatic cardiovascular disease. We excluded those not 


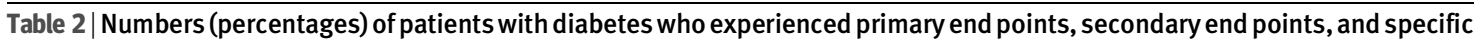
adverse events

\begin{tabular}{|c|c|c|c|c|c|}
\hline Variable & $\begin{array}{l}\text { Aspirin plus } \\
\text { antioxidant } \\
(n=320)\end{array}$ & $\begin{array}{l}\text { Aspirin plus placebo } \\
\qquad(n=318)\end{array}$ & $\begin{array}{l}\text { Placebo plus } \\
\text { antioxidant } \\
(n=320)\end{array}$ & $\begin{array}{c}\text { Placebo plus } \\
\text { placebo }(n=318)\end{array}$ & $\begin{array}{c}\text { P value } \\
\text { (interaction*) }\end{array}$ \\
\hline \multicolumn{6}{|l|}{ Primary end points: } \\
\hline Composite end point† & $58(18)$ & $58(18)$ & $59(18)$ & $57(18)$ & 0.92 \\
\hline $\begin{array}{l}\text { Death from coronary heart disease } \\
\text { or stroke }\end{array}$ & $23(7)$ & $20(6)$ & $19(6)$ & $16(5)$ & 0.90 \\
\hline \multicolumn{6}{|l|}{ Secondary end points: } \\
\hline Death (any cause) & $56(18)$ & $38(12)$ & $59(18)$ & $42(13)$ & 0.93 \\
\hline Death from coronary heart disease & $15(5)$ & $20(6)$ & $15(5)$ & $11(4)$ & 0.24 \\
\hline Stroke death & $8(3)$ & $0(0)$ & $4(1)$ & $5(2)$ & 0.004 \\
\hline Non-fatal myocardial infarction & $21(7)$ & $34(11)$ & $28(9)$ & $28(9)$ & 0.20 \\
\hline Non-fatal stroke & $18(6)$ & $11(4)$ & $18(6)$ & $23(7)$ & 0.14 \\
\hline $\begin{array}{l}\text { Above ankle amputation for critical } \\
\text { limb ischaemia }\end{array}$ & $6(2)$ & $5(2)$ & $4(1)$ & $5(2)$ & 0.69 \\
\hline Transient ischaemic attack & $3(1)$ & $11(4)$ & $8(3)$ & $12(4)$ & 0.25 \\
\hline Coronary artery bypass surgery & $4(1)$ & $6(2)$ & $8(3)$ & $8(3)$ & 0.61 \\
\hline Coronary artery angioplasty & $3(1)$ & $4(1)$ & $4(1)$ & $4(1)$ & 0.78 \\
\hline Development of angina & $31(10)$ & $39(12)$ & $38(12)$ & $40(13)$ & 0.59 \\
\hline Peripheral arterial bypass surgery & $3(1)$ & $4(1)$ & $1(0.3)$ & $4(1)$ & 0.44 \\
\hline Peripheral arterial angioplasty & $6(2)$ & $5(2)$ & $6(2)$ & $7(2)$ & 0.71 \\
\hline $\begin{array}{l}\text { Development of critical limb } \\
\text { ischaemia }\end{array}$ & $13(4)$ & $8(3)$ & $9(3)$ & $10(3)$ & 0.37 \\
\hline Development of claudication & $39(12)$ & $58(18)$ & $58(18)$ & $49(15)$ & 0.032 \\
\hline \multicolumn{6}{|l|}{ Adverse events: } \\
\hline Malignancy & $29(9)$ & $24(8)$ & $36(11)$ & $32(10)$ & 0.85 \\
\hline Gastrointestinal bleeding & $15(5)$ & $13(4)$ & $13(4)$ & $18(6)$ & 0.36 \\
\hline $\begin{array}{l}\text { Gastrointestinal symptoms } \\
\text { including dyspepsia }\end{array}$ & $33(10)$ & $40(13)$ & $36(11)$ & $58(18)$ & 0.31 \\
\hline Arrhythmia & $28(9)$ & $27(9)$ & $22(7)$ & $25(8)$ & 0.67 \\
\hline Allergy, including skin rash & 34 (11) & $38(12)$ & $34(11)$ & $30(9)$ & 0.47 \\
\hline
\end{tabular}

currently free from symptoms of vascular disease at the time of this screening visit. Ankle brachial pressure was measured in asymptomatic patients using a standardised technique. ${ }^{31}$ Training was provided to nurses without experience of measuring this pressure. Patients with an ankle brachial pressure index of less than 1.00 were eligible for inclusion.

After providing written informed consent, patients were randomly assigned to one of four treatment groups: aspirin plus antioxidant, aspirin plus placebo, antioxidant plus placebo, or double placebo. The allocation sequence used randomised permuted blocks of eight and was computer generated by the trial statisticians. To ensure allocation concealment an independent pharmacist packaged the drugs into numbered containers. Recruiting nurses dispensed the trial drugs on the day of randomisation, under the authority of the consultant or primary care doctor. Participants also received standard therapy as appropriate (for example, statins, $\beta$ blockers) at the discretion of the investigator and other responsible clinicians. We emphasised to the investigators the use of appropriate background cardiovascular risk reduction therapy according to current international guidelines. The participants, research nurses, and staff involved in providing care were blinded to group assignment.

Follow-up evaluations were done every six months. At these visits we recorded outcome events, adverse events, and interventions. The results of electrocardiography were recorded at the baseline visit and annually thereafter. The electrocardiograms were reviewed manually for evidence of silent myocardial infarction on the basis of criteria from the Minnesota code. When relevant, a copy of data from hospital admissions was obtained for use by the committee deciding on the presence or absence of a specific end point using predefined criteria. For example, any electrocardiograms obtained from a hospital admission in the case of a suspected myocardial infarction were also coded using the criteria of the Minnesota code so that the appearances of the electrocardiograms were considered in a uniform manner along with clinical and biochemical data in reaching a decision. All primary and secondary end points were adjudicated on a blinded basis by the committee.

\section{Outcome measures}

We used two hierarchical composite primary end points: death from coronary heart disease or stroke, 
non-fatal myocardial infarction or stroke, or above ankle amputation for critical limb ischaemia; and death from coronary heart disease or stroke. Definitions for these events were according to the World Health Organization criteria for the diagnosis of coronary events and strokes (fatal and non-fatal).

The main secondary end points were all cause mortality, non-fatal myocardial infarction, and occurrence of other vascular events, including stroke, transient ischaemic attack, coronary or peripheral arterial bypass surgery, coronary or peripheral arterial angioplasty, development of angina, claudication, or critical limb ischaemia.

\section{Power calculations}

The event rate for similar end points in patients with asymptomatic peripheral arterial disease in the Edinburgh artery study ${ }^{32}$ was $4 \%$ per annum. The event rate in the literature at the time of the start of the trial for patients with diabetes was between twofold and threefold that of the population without diabetes. ${ }^{1-3}$ We originally planned to recruit 1600 participants and follow-up each for four years. If only one treatment was effective this would provide $90 \%$ power to detect a $25 \%$ relative reduction in a four year event rate of $28 \%(8 \%$ per annum) as significant at the $5 \%$ level. This equates to 392 events occurring during the trial. With this sample size but both treatments equally effective, so slightly lower overall event rates, 343 events would be expected in the four years of follow-up. This would still provide greater than $80 \%$ power to detect for each treatment the same relative reduction in event rate as significant.

A slower than expected recruitment rate and lower event rates led to ongoing consideration of recruitment and termination dates by the data monitoring and ethics committee, trial steering committee, and funding body. Eventually 1276 patients were recruited and the final power calculations, undertaken in 2003, projected that if follow-up continued until June 2006 then 256 events would be expected to occur during the trial. This would give $73 \%$ power to detect a $25 \%$ relative reduction in event rate and $89 \%$ power to detect a $30 \%$ reduction in event rate if only one treatment was effective.

\section{Statistical analysis}

The statistical analysis followed the plan determined at the start of the trial. The primary and secondary end points were measures of survival. Accordingly, we used a

Table 3 - Comparison between aspirin and no aspirin groups in number (percentage) of patients with diabetes who experienced primary end points, secondary end points, and specific adverse events

\begin{tabular}{|c|c|c|c|c|}
\hline Variables & Aspirin $(n=638)$ & No aspirin $(n=638)$ & Effect estimate* $(95 \% \mathrm{Cl})$ & $P$ value \\
\hline \multicolumn{5}{|l|}{ Primary end points: } \\
\hline Composite end point $†$ & $116(18.2)$ & $117(18.3)$ & $0.98(0.76$ to 1.26$)$ & 0.86 \\
\hline $\begin{array}{l}\text { Death from coronary heart disease or } \\
\text { stroke }\end{array}$ & $43(6.7)$ & $35(5.5)$ & $1.23(0.79$ to 1.93$)$ & 0.36 \\
\hline \multicolumn{5}{|l|}{ Secondary end points: } \\
\hline Death (any cause) & $94(14.7)$ & $101(15.8)$ & $0.93(0.71$ to 1.24$)$ & 0.63 \\
\hline Coronary heart disease death & $35(5.5)$ & $26(4.1)$ & $1.35(0.81$ to 2.25$)$ & 0.24 \\
\hline Stroke death & $8(1.3)$ & $9(1.4)$ & 0.89 (0.34 to 2.30$)$ & 0.80 \\
\hline Non-fatal myocardial infarction & $55(8.6)$ & $56(8.8)$ & 0.98 (0.68 to 1.43$)$ & 0.93 \\
\hline Non-fatal stroke & $29(4.6)$ & $41(6.4)$ & $0.71(0.44$ to 1.14$)$ & 0.15 \\
\hline $\begin{array}{l}\text { Above ankle amputation for critical } \\
\text { limb ischaemia }\end{array}$ & $11(1.7)$ & $9(1.4)$ & 1.23 (0.51 to 2.97$)$ & 0.64 \\
\hline Transient ischaemic attack & $14(2.2)$ & $20(3.1)$ & 0.70 (0.36 to 1.39$)$ & 0.31 \\
\hline Coronary artery bypass surgery & $10(1.6)$ & $16(2.5)$ & $0.62(0.28$ to 1.38$)$ & 0.24 \\
\hline Coronary artery angioplasty & $7(1.1)$ & $8(1.3)$ & $0.88(0.32$ to 2.43$)$ & 0.81 \\
\hline Development of angina & $70(11.0)$ & $78(12.2)$ & $0.90(0.66$ to 1.25$)$ & 0.54 \\
\hline Peripheral arterial bypass surgery & $7(1.1)$ & $5(0.8)$ & $1.41(0.45$ to 4.43$)$ & 0.56 \\
\hline Peripheral arterial angioplasty & $11(1.7)$ & $13(2.0)$ & 0.85 (0.38 to 1.89$)$ & 0.68 \\
\hline $\begin{array}{l}\text { Development of critical limb } \\
\text { ischaemia }\end{array}$ & $21(3.3)$ & $19(3.0)$ & 1.11 (0.60 to 2.06$)$ & 0.75 \\
\hline Development of claudication & $97(15.2)$ & $107(16.8)$ & 0.89 (0.68 to 1.18$)$ & 0.42 \\
\hline \multicolumn{5}{|l|}{ Adverse events: } \\
\hline Malignancy & $53(8.3)$ & $68(10.7)$ & $0.76(0.52$ to 1.11$)$ & 0.15 \\
\hline Gastrointestinal bleeding & $28(4.4)$ & $31(4.9)$ & 0.90 (0.53 to 1.52$)$ & 0.69 \\
\hline $\begin{array}{l}\text { Gastrointestinal symptoms, } \\
\text { including dyspepsia }\end{array}$ & $73(11.4)$ & $94(14.7)$ & 0.77 (0.55 to 1.08$)$ & 0.081 \\
\hline Arrhythmia & $55(8.6)$ & $47(7.4)$ & $1.19(0.79$ to 1.78$)$ & 0.41 \\
\hline Allergy including skin rash & $72(11.3)$ & $64(10.0)$ & $1.14(0.80$ to 1.63$)$ & 0.47 \\
\hline
\end{tabular}

*Hazard ratios (aspirin $v$ no aspirin) for primary and secondary end points and odds ratios (aspirin $v$ no aspirin) for adverse events.

tDeath from coronary heart disease or stroke, non-fatal myocardial infarction or stroke, or above ankle amputation for critical limb ischaemia. 
Cox proportional hazards model as the primary method of analysis. We assessed the interventions by fitting terms corresponding to aspirin, antioxidants, and the interaction between these treatments. As there was no evidence of interaction we dropped this term, allowing the overall effect of each intervention to be assessed. We assessed the assumption of proportionality of hazards and we used Kaplan-Meier plots for the survival experience by treatment group. Specific adverse events were assessed using logistic regression with terms corresponding to aspirin, antioxidants, and the interaction between these treatments. As we found no

\begin{tabular}{|c|c|c|c|c|}
\hline Variables & Antioxidant $(n=640)$ & $\begin{array}{l}\text { No antioxidant } \\
\quad(n=636)\end{array}$ & $\begin{array}{l}\text { Effect estimate* } \\
(95 \% \mathrm{Cl})\end{array}$ & $P$ value \\
\hline \multicolumn{5}{|l|}{ Primary end points: } \\
\hline $\begin{array}{l}\text { Composite end } \\
\text { point† }\end{array}$ & $117(18.3)$ & $116(18.2)$ & $1.03(0.79$ to 1.33$)$ & 0.85 \\
\hline $\begin{array}{r}\text { Death from coronary } \\
\text { heart disease or stroke }\end{array}$ & $42(6.6)$ & $36(5.7)$ & 1.21 (0.78 to 1.89$)$ & 0.40 \\
\hline \multicolumn{5}{|l|}{ Secondary end points: } \\
\hline Death (any cause) & $115(18.0)$ & $80(12.6)$ & 1.49 (1.12 to 1.99$)$ & 0.006 \\
\hline $\begin{array}{l}\text { Coronary heart } \\
\text { disease death }\end{array}$ & $30(4.7)$ & $31(4.9)$ & 1.01 (0.61 to 1.66$)$ & 0.99 \\
\hline Stroke death & $12(1.9)$ & $5(0.8)$ & 2.49 (0.88 to 7.06$)$ & 0.087 \\
\hline $\begin{array}{l}\text { Non-fatal myocardial } \\
\text { infarction }\end{array}$ & $49(7.7)$ & $62(9.7)$ & 0.81 (0.55 to 1.17$)$ & 0.26 \\
\hline Non-fatal stroke & $36(5.6)$ & $34(5.4)$ & 1.08 (0.68 to 1.73$)$ & 0.74 \\
\hline $\begin{array}{l}\text { Above ankle } \\
\text { amputation for critical } \\
\text { limb ischaemia }\end{array}$ & $10(1.6)$ & $10(1.6)$ & 1.04 (0.43 to 2.50$)$ & 0.93 \\
\hline $\begin{array}{l}\text { Transient ischaemic } \\
\text { attack }\end{array}$ & $11(1.7)$ & $23(3.6)$ & $0.49(0.24$ to 1.00$)$ & 0.050 \\
\hline $\begin{array}{l}\text { Coronary artery } \\
\text { bypass surgery }\end{array}$ & $12(1.9)$ & $14(2.2)$ & 0.89 (0.41 to 1.91$)$ & 0.76 \\
\hline $\begin{array}{l}\text { Coronary artery } \\
\text { angioplasty }\end{array}$ & $7(1.1)$ & $8(1.3)$ & $0.89(0.32$ to 2.46$)$ & 0.82 \\
\hline $\begin{array}{l}\text { Development of } \\
\text { angina }\end{array}$ & $69(10.8)$ & $79(12.4)$ & 0.89 (0.65 to 1.23$)$ & 0.49 \\
\hline $\begin{array}{l}\text { Peripheral arterial } \\
\text { bypass surgery }\end{array}$ & $4(0.6)$ & $8(1.3)$ & 0.52 (0.16 to 1.72$)$ & 0.28 \\
\hline $\begin{array}{l}\text { Peripheral arterial } \\
\text { angioplasty }\end{array}$ & $12(1.9)$ & $12(1.9)$ & 1.05 (0.47 to 2.33$)$ & 0.92 \\
\hline $\begin{array}{l}\text { Development of } \\
\text { critical limb ischaemia }\end{array}$ & $22(3.4)$ & $18(2.8)$ & 1.28 (0.68 to 2.38 ) & 0.45 \\
\hline $\begin{array}{l}\text { Development of } \\
\text { claudication }\end{array}$ & $97(15.2)$ & $107(16.8)$ & $0.94(0.72$ to 1.24$)$ & 0.67 \\
\hline \multicolumn{5}{|l|}{ Adverse events: } \\
\hline Malignancy & $65(10.2)$ & $56(8.8)$ & $1.17(0.80$ to 1.71$)$ & 0.41 \\
\hline $\begin{array}{l}\text { Gastrointestinal } \\
\text { bleeding }\end{array}$ & $28(4.4)$ & $31(4.9)$ & $0.89(0.53$ to 1.51$)$ & 0.67 \\
\hline $\begin{array}{l}\text { Gastrointestinal } \\
\text { symptoms, including } \\
\text { dyspepsia }\end{array}$ & $69(10.8)$ & $98(15.4)$ & 0.66 (0.48 to 0.92$)$ & 0.015 \\
\hline Arrhythmia & $50(7.8)$ & $52(8.2)$ & 0.95 (0.64 to 1.43$)$ & 0.81 \\
\hline $\begin{array}{l}\text { Allergy including } \\
\text { skin rash }\end{array}$ & $68(10.6)$ & $68(10.7)$ & $0.99(0.70$ to 1.42$)$ & 0.97 \\
\hline
\end{tabular}

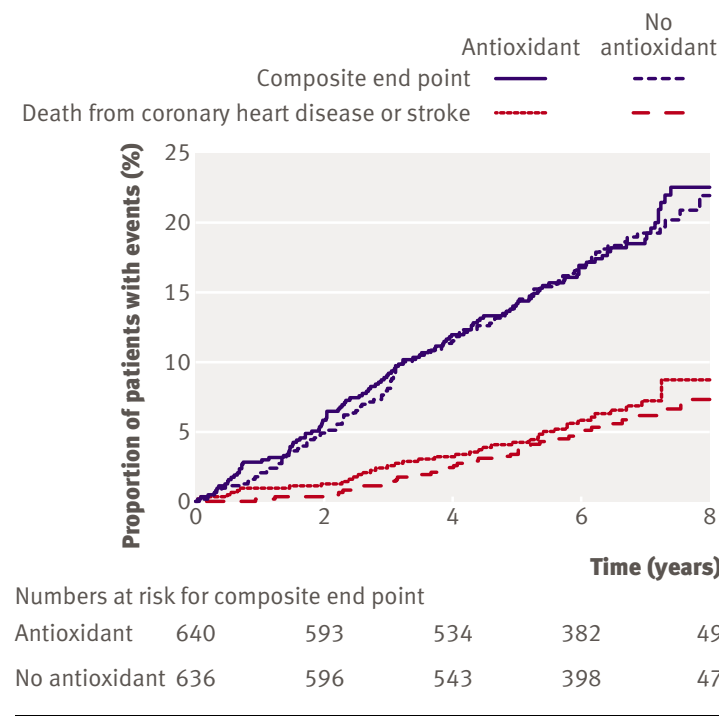

Fig 4 Kaplan-Meier estimates for antioxidant and no antioxidant groups of proportion of patients who experienced the composite end point of death from coronary heart disease or stroke, non-fatal myocardial infarction or stroke, or above ankle amputation for critical limb ischaemia; and death from coronary heart disease or stroke

evidence of interaction we dropped this term, allowing the overall effect of each intervention to be assessed. All analyses were done on an intention to treat basis, with two tailed tests of significance used throughout.

The trial was designed, planned, and executed by the trial steering committee in collaboration with the UK Medical Research Council. The trial was done in accordance with good clinical practice regulations. ${ }^{33}$ Experienced research nurses collected the data, which were entered and analysed by the Medical Statistics Unit, University of Edinburgh. The progress of the study was monitored throughout by the data monitoring and ethics committee. This committee met at six monthly or yearly intervals depending on the stage of the trial. No formal stopping rules were used. The principle employed was that early termination for efficacy or futility would only occur if the evidence was assessed to be strong enough to influence practice.

\section{RESULTS}

Adults aged 40 or more with diabetes were screened between November 1997 and July 2001. A total of 1670 patients were potentially eligible and had an ankle brachial pressure index of 0.99 or less. Of these, 1276 $(76.4 \%)$ gave written informed consent and were randomised; 320 to receive aspirin tablets plus antioxidant capsules, 318 to receive aspirin tablets plus placebo capsules, 320 to receive placebo tablets plus antioxidant capsules, and 318 to receive placebo tablets plus placebo capsules. The treatment groups were similar for baseline characteristics (table 1).

Follow-up

Figure 1 shows the flow of participants in the trial. Overall, 1074 participants had their final follow-up in 
2006, six had moved away and were lost to follow-up, one withdrew consent after four years, and 195 died during the trial. The median length of follow-up for randomised participants was 6.7 years and for those with a final follow-up in 2006 follow-up ranged from 4.5 to 8.6 years. A total of 8127 patient years of followup were completed.

\section{End points}

Overall, 233 participants experienced the composite primary end point of death from coronary heart disease or stroke, non-fatal myocardial infarction or stroke, or above ankle amputation for critical limb ischaemia, an overall event rate of 2.9 per 100 patient years. Seventy eight participants died from coronary heart disease or stroke, an event rate of 1.0 per 100 patient years. Table 2 shows the proportion of participants by treatment group who experienced each end point or specific adverse event.

The interaction between the aspirin and antioxidant treatments was not statistically significant either for the composite primary end point $(\mathrm{P}=0.88)$ or for death from coronary heart disease or stroke $(\mathrm{P}=0.95)$. In addition, the interaction between the two treatments was statistically significant for only two of the secondary end points - death from stroke $(\mathrm{P}=0.004)$ and the development of claudication $(\mathrm{P}=0.032)$. No evidence was found of an interaction for the specific adverse events. Because there was no evidence of an interaction between aspirin and antioxidant, patients in the two groups randomised to receive aspirin were compared with those in the two groups randomised to receive placebo tablets (no aspirin), and patients in the two groups randomised to receive antioxidant were compared with those in the two groups randomised to receive placebo capsules (no antioxidant).

\section{Aspirin versus no aspirin}

Table 3 shows the proportion of participants with each of the primary and secondary end points in the aspirin and no aspirin groups. Figure 2 shows the cumulative percentages of patients over time who experienced each of the primary end points. The differences

\begin{tabular}{|c|c|c|c|c|}
\hline Causes of death & $\begin{array}{c}\text { Aspirin plus } \\
\text { antioxidant }(n=56)\end{array}$ & $\begin{array}{c}\text { Aspirin plus } \\
\text { placebo }(n=38)\end{array}$ & $\begin{array}{c}\text { Placebo plus } \\
\text { antioxidant }(n=59)\end{array}$ & $\begin{array}{l}\text { Placebo plus } \\
\text { placebo }(n=42)\end{array}$ \\
\hline Myocardial infarction & 11 & 10 & 8 & 5 \\
\hline $\begin{array}{l}\text { Other coronary heart } \\
\text { disease }\end{array}$ & 4 & 10 & 7 & 6 \\
\hline \multicolumn{5}{|l|}{ Stroke: } \\
\hline Ischaemic & 3 & 0 & 3 & 2 \\
\hline Haemorrhagic & 2 & 0 & 1 & 2 \\
\hline Unknown cause & 3 & 0 & 0 & 1 \\
\hline Other cardiac & 5 & 0 & 4 & 1 \\
\hline Other vascular & 3 & 1 & 2 & 2 \\
\hline Cancer & 16 & 9 & 18 & 13 \\
\hline Trauma & 0 & 0 & 2 & 0 \\
\hline Other & 9 & 8 & 14 & 10 \\
\hline
\end{tabular}

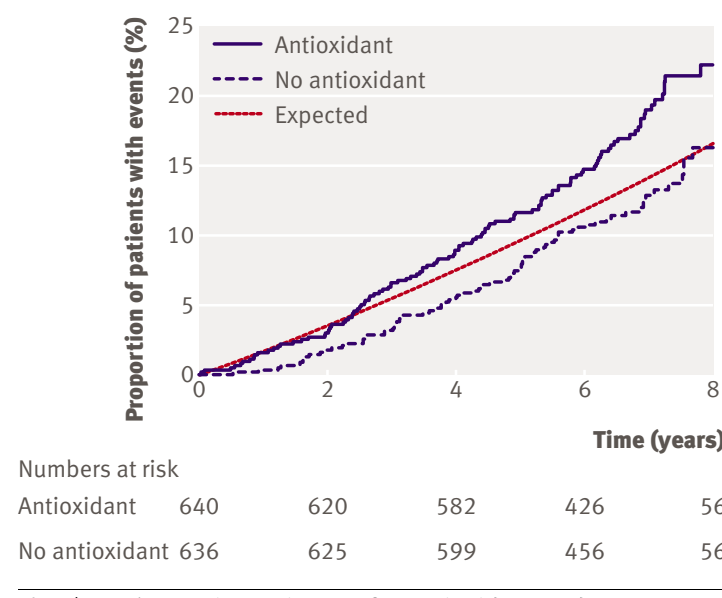

Fig 5 | Kaplan-Meier estimates for antioxidant and no antioxidant groups of proportion of patients who died from any cause, compared with proportion expected based on age and sex specific population rates for Scotland, 2002

between these two groups were not statistically significant for either of the primary end points.

Figure 3 presents the cumulative percentages of patients over time who died from any cause, along with the percentage expected for all patients based on age and sex specific mortality rates for Scotland, 2002 (General Registrar Office, Scotland). No statistically significant differences were found between the aspirin and no aspirin groups for any of the secondary end points. Specific adverse event rates were not statistically significantly different between the aspirin and no aspirin groups (table 3).

\section{Antioxidant versus no antioxidant}

Table 4 presents the proportion of patients who experienced each of the primary and secondary end points in the antioxidant and no antioxidant groups. Figure 4 shows the cumulative percentages of patients over time who experienced each of the primary end points. No statistically significant differences were found between these two groups for either of the primary end points.

Figure 5 shows the cumulative percentages of patients over time who died from any cause, along with the percentage expected for all patients based on age and sex specific population rates for Scotland. The increase in numbers of deaths from any cause in the antioxidant group compared with the no antioxidant group was statistically significant $(\mathrm{P}=0.006)$. This difference in all cause mortality seems to be partly due to a relative deficiency of deaths in the no antioxidant group compared with an age and sex matched Scottish population and partly due to a relative excess of deaths in the antioxidant group. No statistically significant differences were found between the antioxidant and no antioxidant groups for any of the other secondary end points.

Specific adverse event rates were not statistically significantly different in the antioxidant and no antioxidant groups, except for gastrointestinal symptoms 
Table 6 | Comparison of aspirin and no aspirin groups in subgroups of specified baseline characteristics for primary end points

\begin{tabular}{|c|c|c|c|c|c|c|}
\hline \multirow[b]{2}{*}{ Primary end point } & \multicolumn{2}{|c|}{ Aspirin } & \multicolumn{2}{|c|}{ No aspirin } & \multirow[b]{2}{*}{ Hazard ratio $(95 \% \mathrm{Cl})$} & \multirow[b]{2}{*}{$P$ value* } \\
\hline & No of patients & $\begin{array}{c}\text { No (\%) with } \\
\text { event }\end{array}$ & No of patients & $\begin{array}{c}\text { No (\%) with } \\
\text { event }\end{array}$ & & \\
\hline \multicolumn{7}{|c|}{ Composite end point $†$} \\
\hline \multicolumn{7}{|l|}{ Age (years): } \\
\hline$<60$ & 297 & $38(12.8)$ & 315 & $36(11.4)$ & $1.11(0.70$ to 1.75$)$ & \multirow{2}{*}{0.44} \\
\hline$\geq 60$ & 341 & $78(22.9)$ & 323 & $81(25.1)$ & $0.89(0.65$ to 1.21$)$ & \\
\hline Women & 352 & $48(13.6)$ & 361 & $55(15.2)$ & $0.89(0.60$ to 1.31$)$ & \multirow{2}{*}{0.54} \\
\hline Men & 286 & $68(23.8)$ & 277 & $62(22.4)$ & $1.04(0.74$ to 1.47$)$ & \\
\hline \multicolumn{7}{|l|}{$\begin{array}{l}\text { Ankle brachial } \\
\text { pressure index: }\end{array}$} \\
\hline$\leq 0.90$ & 314 & $59(18.8)$ & 332 & $75(22.6)$ & $0.81(0.58$ to 1.14$)$ & \multirow{2}{*}{0.089} \\
\hline 0.91-0.99 & 324 & $57(17.6)$ & 306 & $42(13.7)$ & $1.28(0.86$ to 1.91$)$ & \\
\hline \multicolumn{7}{|c|}{ Death from coronary heart disease or stroke } \\
\hline \multicolumn{7}{|l|}{ Age (years): } \\
\hline$<60$ & 297 & $10(3.4)$ & 315 & $10(3.2)$ & 1.07 (0.44 to 2.56$)$ & \multirow{2}{*}{0.77} \\
\hline$\geq 60$ & 341 & $33(9.7)$ & 323 & $25(7.7)$ & 1.24 (0.74 to 2.09$)$ & \\
\hline Women & 352 & $17(4.8)$ & 361 & $16(4.4)$ & $1.09(0.55$ to 2.16$)$ & \multirow{2}{*}{0.68} \\
\hline Men & 286 & $26(9.1)$ & 277 & $19(6.9)$ & $1.33(0.73$ to 2.40$)$ & \\
\hline \multicolumn{7}{|l|}{$\begin{array}{l}\text { Ankle brachial } \\
\text { pressure index: }\end{array}$} \\
\hline$\leq 0.90$ & 314 & $22(7.0)$ & 332 & $24(7.2)$ & $0.96(0.54$ to 1.71$)$ & \multirow{2}{*}{0.17} \\
\hline $0.91-0.99$ & 324 & $21(6.5)$ & 306 & $11(3.6)$ & 1.84 (0.89 to 3.82$)$ & \\
\hline
\end{tabular}

*Test for heterogeneity of treatment effect in subgroups.

†Death from coronary heart disease or stroke, non-fatal myocardial infarction or stroke, or above ankle amputation for critical limb ischaemia

including dyspepsia $(\mathrm{P}=0.015)$, which were reported by more patients in the no antioxidant groups.

\section{Cause of death}

The end points committee classified the deaths as coronary heart disease, stroke, other cardiac, other vascular, cancer, trauma, or other. The deaths from coronary heart disease were further classified as being due to myocardial infarction or other coronary heart disease, whereas the deaths from stroke were classified as ischaemic, haemorrhagic, or of unknown cause. More deaths occurred in the antioxidant groups than no antioxidant groups for all the categories except other coronary heart disease (table 5).

\section{Subgroup analyses}

Although subgroup analyses were planned, the trial steering committee asked that analyses of the primary end points compared aspirin and no aspirin groups by subgroups of age, sex, or ankle brachial pressure index. This was because of concern that particular patients with an ankle brachial pressure index of less than 0.90 , which defines peripheral arterial disease, may have been at higher risk and so might have shown some benefit in this subgroup. The difference in treatment effect between the subgroups was not statistically significant for any of the three characteristics (table 6).

\section{Trial drugs}

The cumulative percentage of patients who stopped taking the tablets (aspirin or placebo) before they experienced the composite primary end point, died, moved abroad, withdrew consent, or completed the study was $14 \%$ by the end of one year. Thereafter withdrawal from trial therapy was fairly constant, leading to a cumulative rate of $50 \%$ after five years.

\section{DISCUSSION}

We evaluated the effect of aspirin or antioxidant on cardiovascular events and mortality in a large cohort of people with diabetes mellitus with asymptomatic peripheral arterial disease. These two clinical criteria were selected for study as guidelines ${ }^{15-18}$ were being published, without evidential support, recommending aspirin use as primary prevention of cardiovascular disease in patients with diabetes mellitus and with asymptomatic peripheral arterial disease. We found no evidence of benefit from either aspirin or antioxidant treatment on the composite hierarchical primary end points of cardiovascular events and cardiovascular mortality. The lower 95\% confidence limits for these primary end points, however, only just excluded a $25 \%$ benefit for aspirin and a $23 \%$ benefit for antioxidant, whereas the upper $95 \%$ confidence limits only just excluded a $27 \%$ increase in cardiovascular events for aspirin and a $34 \%$ increase for antioxidant. Clinically important benefits are unlikely from the results of this study, although it is possible that small effects may be shown with larger trials continued for a longer time.

We preferred the $2 \times 2$ factorial design to two separate trials because it had major advantages. ${ }^{30}$ Firstly, it greatly reduced the number of patients needed to achieve the specified statistical power on the assumption that aspirin and antioxidant did not interact. Secondly, using such a design provided an opportunity for testing the interaction between the two 


\begin{tabular}{|c|}
\hline WHAT IS ALREADY KNOWN ON THIS TOPIC \\
\hline $\begin{array}{l}\text { Aspirin is effective in the secondary prevention of } \\
\text { cardiovascular events in patients with symptomatic } \\
\text { peripheral arterial disease and with or without diabetes }\end{array}$ \\
\hline $\begin{array}{l}\text { Aspirin is responsible for significant gastrointestinal } \\
\text { morbidity }\end{array}$ \\
\hline $\begin{array}{l}\text { No large intervention trial has shown any reduction of events } \\
\text { with antioxidant intervention }\end{array}$ \\
\hline WHAT THIS STUDY ADDS \\
\hline $\begin{array}{l}\text { Aspirin was not effective in the primary prevention of } \\
\text { cardiovascular events in patients with asymptomatic } \\
\text { peripheral arterial disease and diabetes }\end{array}$ \\
\hline $\begin{array}{l}\text { Antioxidants showed no benefit on cardiovascular events in } \\
\text { his population }\end{array}$ \\
\hline
\end{tabular}

interventions, although the power to detect an interaction was low. This design yields double the information of single factorial designs.

In examining why aspirin may have been ineffective the question was asked as to whether these patients were at sufficient risk, in terms of peripheral arterial disease, as the cut-off point of an ankle brachial pressure index of 0.99 or less is higher than that used to define peripheral arterial disease in the population $(<0.9) .{ }^{31}$ A subgroup analysis did not, however, find evidence of a difference in effect of aspirin between those with an index of 0.91-0.99 and those below this level. Furthermore, one of the current major interventions in the specialty of diabetes mellitus is statin therapy. Calculations by two of the centres (DM and $\mathrm{CK}$ ) in over 10000 people with diabetes showed a mean total cholesterol level of $6.0 \mathrm{mmol} / \mathrm{l}$ in 1996 decreasing to $4.3 \mathrm{mmol} / \mathrm{l}$ in 2007 . As aspirin was the first drug to have an evidence base for secondary prevention of cardiovascular disease it is always given to patients in subsequent trials and it might be asked if aspirin does indeed provide additional benefit when statins are used to good effect.

The importance of the neutral effect of aspirin on cardiovascular events is that this drug is not without side effects. ${ }^{23}$ Aspirin is the most commonly prescribed drug in Scotland, with about 544438 person years exposure per year in 2002. The number of prescriptions is increasing. The overwhelming majority of this, in the region of Tayside at least, is prescription based, with only about $7 \%$ being from over the counter use. Aspirin is one of the top 10 causes of adverse drug events reported to the Commission on Human Medicines. Gastrointestinal bleeding is associated with general use of non-steroidal anti-inflammatory drugs in over $80 \%$ of reported cases, and $87 \%$ of that use is associated with aspirin, either alone or with other non-steroidal anti-inflammatory drugs. ${ }^{34}$ The risk of a bleeding event increases with age and also continuous exposure. ${ }^{23}$ Although the calculated risk of major bleeding is relatively small, ${ }^{35}$ the number of people taking aspirin is relatively large and therefore in population terms aspirin induced bleeding is a major problem. In a meta-analysis the number needed to treat to cause an adverse event has been calculated as $248,{ }^{36}$ and this is relevant to the large and increasing population with diabetes.

Of concern was the fact that there was a tendency to harm in the antioxidant group. It should be noted that the increase in number of deaths in the antioxidant groups seems to partly reflect better survival than expected of the groups who did not receive antioxidants, rather than just an obvious negative effect of the antioxidants. Thus this may at least in part be a difference achieved by chance. This agrees with recently published work, ${ }^{37}$ and these data should be added to future systematic reviews and meta-analyses. Anecdotally, many people with diabetes supplement with antioxidants after major publicity in the lay press of a deficiency in antioxidants in such people. We found no evidence for this perceived benefit from our study.

We found no evidence to support the use of either aspirin or antioxidants in the primary prevention of cardiovascular events and mortality in people with diabetes. Aspirin should, however, still be given for secondary prevention of cardiovascular disease in people with diabetes mellitus, when the evidence base is convincing, and the results of this study must not detract from this important standard of care.

We thank Bayer for donating the aspirin and placebo tablets, Scotia Pharmaceuticals (formerly Cardinal) for the anitioxidant capsules and matching placebo, and the study nurse team of the prevention of progression of arterial disease and diabetes trial. Members of the Prevention of Progression of Arterial Disease and Diabetes Study Group. Medical Research Council steering committee: JBel (principal investigator), IC, SC, AMacC (chair), RT, and representatives of the Medical Research Council (various). Data and safety monitoring committee: Keith Fox, Desmond G Johnston, Gordon Murray, and JS (chair). End points committee: PM (chair), SMcE, JMCK, SP, RMacW, JBan, and Mairi Stirling Contributing centres: Dundee-GL, RJ, AM, and Ray Newton (Ninewells Hospital); Dunfermline-AJ (Queen Margaret Hospital); Edinburgh West —JMcK (Western General Hospital); Falkirk—J Doig and NP (Falkirk and District Royal Infirmary); Glasgow-CS (Southern General Hospital), DG (Stobhill), Colin Kesson (Victoria Infirmary), and JP (Royal Infirmary); East Kilbride-Susan Benbow (Hairmyres and Stonehouse); Kirkcaldy-IC (Royal Victoria Hospital); Livingstone-Stuart Gray (St John's Hospital); Perth—AC (Perth Royal Infirmary); Monklands_DM (Monklands Hospital); Motherwell and Wishaw_IO'B (Wishaw General); StirlingSheila Reith and CK (Stirling Royal Infirmary). Nursing staff: JBan (senior research nurse). Royal College of Physicians Edinburgh Diabetes Registry Group, and West of Scotland clinicians: JBel, IC, John Chalmers, Joycelin Chalmers, AC, John Doig, David Fraser, Stuart Gray, Victor Hawthorne, RJ, RL (study statistician), GL, Susan Lewis, Derreck McCullough, SMcE, Margaret MacLeod, John McKnight, David Matthews, Andrew Morris, Ray Newton, NP, RP (study statistician), Sheila Reit, Mary Scott, Tanya Siann, Alan Smith, and James Walker.

Contributors: All authors were members of the Royal College of Physicians Edinburgh and as such helped in the development and completion of the protocol and the project. The writing committee consisted of JBel, RP, and RL but all authors had input into the written document.

Funding: This work was supported by the Medical Research Council grant number G9534799. All researchers were independent of the funder. Competing interests: None declared.

Ethical approval: This work was approved by the local research ethics committees of all participating centres and by a multiresearch ethics committee.

Provenance and peer review: Not commissioned; externally peer reviewed. 
1 Howard BV, Best LG, Galloway JM, Howard WJ, Jones K, Lee ET, et al. Coronary heart disease risk equivalence in diabetes depends on concomitant risk factors. Diabetes Care 2006:29;391-7.

2 Abraira C, Colwell J, Nuttall F, Sawin CT, Henderson W, Comstock JP, et al. Cardiovascular events and correlates in the veterans affairs diabetes feasibility trial: veterans affairs cooperative study on glycemic control and complications in type II diabetes. Arch Intern Med 1997;157:181-8.

3 Diabetes Control and Complications Trial Research Group. Effect of intensive diabetes management on macrovascular events and risk factors in the diabetes control and complications trial. Am J Cardiol 1995;75:894-903.

4 Antithrombotic Trialists' Collaboration. Collaborative meta-analysis of randomised trials of antiplatelet therapy for prevention of death, myocardial infarction, and stroke in high risk patients. $B M$ J 2002;324:71-86.

5 Sivenius J, Laakso M, Riekkinen P Sr, Smets P, Lowenthal A. European stroke prevention study: effectiveness of antiplatelet therapy in diabetic patients in secondary prevention of stroke. Stroke 1992;23:851-4.

6 Leng GC, Lee AJ, Fowkes FGR, Whiteman M, Dunbar J, Housley E, et al. Incidence, natural history and cardiovascular events in symptomatic and asymptomatic peripheral arterial disease in the general population. Int J Epidemiol 1996;25:1172-81.

7 Criqui MH, Langer RD, Fronek A, Feigelson HS, Klauber MR, McCann TJ, et al. Mortality over a period of 10 years in patients with peripheral arterial disease. N Engl J Med 1992;326:381-6.

8 Dormandy JA, Rutherford RB, for the TransAtlantic Inter-Society Consensus (TASC) Working Group. Management of peripheral arteria disease (PAD). J Vasc Surg 2000;31:S1-296.

9 Baigent C, Keech A, Kearney PM, Blackwell L, Buck G, Pollicino C, et al. Efficacy and safety of cholesterol-lowering treatment: prospective meta-analysis of data from 90056 participants in 14 randomised trials of statins. Lancet 2005;366:1267-78.

10 CAPRIE steering committee. A randomised, blinded, trial of clopidogrel versus aspirin in patients at risk of ischaemic events (CAPRIE). Lancet 1996;348:1329-39.

11 Tierney S, Fennessy F, Hayes DB. ABC of arterial and vascular disease: secondary prevention of peripheral vascular disease. $B M J$ 2000;320:1262-5.

12 Belch J), Topol EJ, Agnelli G, Bertrand M, Califf RM, Clement DL, et al. Critical issues in peripheral arterial disease detection and management. A call to action. Arch Intern Med 2003;163:884-92.

13 Scottish Intercollegiate Guidelines Network. Diagnosis and management of peripheral arterial disease: a national clinical guideline. 2006. No 89. www.sign.ac.uk/pdf/sign89.pdf.

14 Norgren L, Hiatt WR, Dormandy J, Nehler MR, Harris KH, Fowkes FGR, et al. Inter-society consensus for the management of peripheral arterial disease (TASC II). Eur I Vasc Endovasc Surg 2007;33(suppl 1):S1-75.

15 Joint British Societies' guidelines on prevention of cardiovascular disease in clinical practice: British Cardiac Society, British Hypertension Society, Diabetes UK, HEART UK, Primary Care Cardiovascular Society, the Stroke Association. Heart 2005;91(suppl V):v1-52.

16 Scottish Intercollegiate Guidelines Network. Risk estimation and the prevention of cardiovascular disease. No 97. 2007. www.sign.ac.uk/ pdf/sign97.pdf.

17 Buse JB, Ginsberg HH, Bakris GL, Clark NG, Costa F, Eckel R, et al. Primary prevention of cardiovascular diseases in people with diabetes mellitus: a scientific statement from the American Heart Association and the American Diabetes Association. Diabet Care 2007;30:162-72.
18 Colwell JA, American Diabetes Association. Aspirin therapy in diabetes: Diabet Care 2003;26 (suppl 1):S87-8.

19 ACC/AHA. Guidelines for the management of patients with periphera arterial disease (lower extremity, renal, mesenteric, and abdominal aortic): a collaborative report from the American Association for Vascular Surgery/Society for Vascular Surgery, Society for Cardiovascular Angiography and Interventions, Society for Vascular Medicine and Biology, Society of Interventional Radiology, and the ACC/AHA Task Force on Practice Guidelines (writing committee to develop guidelines for the management of patients with peripheral arterial disease). 2006. www.acc.org/clinical/guidelines/pad/index. pdf.

20 Sacco M, Pellegrini F, Roncaglioni MC, Avanzini F, Tognoni G, Nicolucci A. Primary prevention of cardiovascular events with lowdose aspirin and vitamin $E$ in type 2 diabetic patients: results of the primary prevention project (PPP) trial. Diabet Care 2003;26:3264-72.

21 Piechowski-Jozwiak B, Maulaz A, Bogousslavsky J. Secondary prevention of stroke with antiplatelet agents in patients with diabetes mellitus. Cerebrovasc Dis 2005;20(suppl 1):15-23.

22 Cull CA, Neil HAW, Holman RR. Changing aspirin use in patients with type 2 diabetes in the UKPDS. Diabet Med 2004;21:1368-71.

23 MacDonald TM, Morant SV, Robinson GC, Shield MJ, McGilchrist MM, Murray FE, et al. Association of upper gastrointestinal toxicity of nonsteroidal anti-inflammatory drugs with continued exposure: cohort study. BMJ 1997;315:1333-7.

24 Sanmuganathan PS, Ghahramani P, Jackson PR, Wallis EJ, Ramsay LE. Aspirin for primary prevention of coronary heart disease: safety and absolute benefit related to coronary risk derived from meta-analysis of randomised trials. Heart 2001;85:265-71.

25 Lowe GDO. Who should take aspirin for primary prophylaxis of coronary heart disease? Heart 2001;85:245-6

26 Lagarde M, Burtin M, Berciaud P. Increase of platelet thromboxane $A_{2}$ formation and of its plasma half-life in diabetes mellitus. Thromb Res 1980;19:823-30.

27 Jennings PE, Scott NA, Saniabadi AR, Belch JJF. Effects of gliclazide on platelet reactivity and free radicals in type 2 diabetic patients: clinical assessment. Metabolism 1992;5:36-9.

28 Belch JIF, Chopra M, Hutchinson S, Lorimer R, Sturrock RD, Forbes CD, et al. Free radical pathology in chronic arterial disease. J Free Radic Bio Med 1989;6:375-8.

29 Salonen JT. Antixodants and platelets. Ann Med 1989;21:59-62.

30 Cochrane WC, Cox GM. Experimental designs, 2nd edn. New York: Wiley, 1957

31 Elhadd TA, Robb R, Jung RT, Stonebridge PA, Belch JJF. Pilot study of prevalence of asymptomatic peripheral arterial occlusive disease in patients with diabetes attending a hospital clinic. Pract Diabetes Int 1999;16:163-6

32 Fowkes FG, Housley E, Cawood EHH, Macintyre CC, Ruckley CV, Prescott RJ. Edinburgh artery study: prevalence of asymptomatic and symptomatic peripheral arterial disease in the general population. Int J Epidemiol 1991;20:384-91.

33 US Food and Drug Administration. Good clinical practice regulations 2007. www.fda.gov/oc/gcp/guidance.html.

34 Lanas A, Sekar MC, Hirschowitz BI. Objective evidence of aspirin use in both ulcer and nonulcer upper and lower gastrointestinal bleeding. Gastroenterology 1992;103:862-9.

35 Faulkner G, Prichard P, Somerville K, Langman MJ. Aspirin and bleeding peptic ulcers in the elderly. BMJ 1988;297:1311-3.

36 Derry S, Loke YK. Risk of gastrointestinal haemorrhage with long term use of aspirin: meta-analysis. BMJ 2000;321:1183-7.

37 Vivekananthan DP, Penn MS, Sapp SK, Hsu A, Topol EJ. Use of antioxidant vitamins for the prevention of cardiovascular disease. Lancet 2003;361:2017-23.

Accepted: 19 August 2008 